\title{
Falls \& Fall-related Injuries Special Interest Group: a Call to Action
}

\author{
Manuel Montero-Odasso, MD, PhD, AGSF, FRCP ${ }^{1}$, and David B. Hogan, MD, FRCPC ${ }^{2}$ \\ ${ }^{1}$ Division of Geriatric Medicine, Department of Medicine, University of Western Ontario, London, ON; \\ ${ }^{2}$ Division of Geriatric Medicine, Department of Medicine, University of Calgary, Calgary, AB, Canada
}

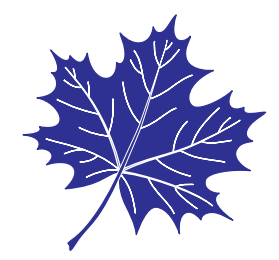

DOI:http://dx.doi.org/10.5770/cgj.19.258

To the Editor,

Both of us want to thank those who were able to participate the exploratory meeting for the establishment of a Canadian Geriatrics Society (CGS) Falls \& Fall-related Injuries Special Interest Group (FALLS SIG) that was held April 16, 2016 during the 36th Annual Scientific Meeting of the Society. This communication provides a summary of the meeting and an update on where we are now.

Falls is a quintessential geriatric syndrome. Its study and the approaches developed for their prevention contributed to the establishment of geriatric medicine as a distinct field of specialty practice. Despite the myriad of studies aimed at improving our understanding of their pathophysiology and the clinical trials designed to establish effective strategies to prevent falls and fall-related injuries, there are still important gaps in what we know about this challenging and complex syndrome. We believe the CGS is a natural organizational home for a pan-Canadian interest group on falls. By bringing a "geriatric perspective" to the table we feel we have much to contribute to this area of inquiry. This would include identifying areas of uncertainty in our knowledge about falls, contributing to fall prevention guidelines, and translating effective approaches to clinical practice. Other national geriatric societies have taken the issue of falls very seriously. As examples, the American Geriatrics Society-led guidelines on fall prevention ${ }^{(1)}$ are widely used, while the British Geriatrics Society hosts an annual international meeting on falls and postural instability. ${ }^{(2)}$

A Special Interest Group (SIG) is a community within a larger organization with a shared interest in advancing a specific area of knowledge, learning, and/or practice. We believe that Society-based SIGs are a potential mechanism to address falls and other clinical issues of importance to CGS members such as delirium, dementia, and frailty. Both the American Geriatrics Society ${ }^{(3)}$ and the British Geriatrics Society ${ }^{(4)}$ have established a number of SIGs.

At the meeting Manuel Montero-Odasso challenged current dogma about fall prevention strategies for those with cognitive impairment. This was followed by an open dialogue about falls, the establishment of a FALLS SIG, and the proposed preliminary objectives and activities for this group. Comments and concerns raised by attendees (in no particular order) included:

1. A desire to eradicate the term mechanical fall. ${ }^{(5)}$

2. There was an identified need for clear and accessible resources on fall prevention for busy clinicians. This could take the form of updated fall prevention guidelines for primary care physicians and easy-to-find material on, for example, the CGS website about falls and fall prevention.

3. The observation that syncopal falls are under-recognized and undertreated.

4. There were a number of comments made about exercise. There was uncertainty on how to prescribe exercise to prevent falls and who should participate in a fall prevention exercise program. Should all persons above a certain age (e.g., 65 years or older) be encouraged to participate in an exercise program (a reasonable suggestion, given the 30\% fall rate in this age group), or should it be the subset of older adults with an elevated risk for a fall injury? What type of exercise program should be recommended? Who can be advised to exercise on their own? Who should attend a supervised program at sites such as senior centres or gyms? Who would require supervision, at least initially, by a health professional (e.g., physiotherapist)?

5. Are there valid, reliable, and practical clinical screening tests that should be used to identify high-risk populations in a variety of settings?

6. How to deal with falls in ERs?

7. How early should fall prevention strategies start? 40s? 50 s? Is it too late when individuals are older?

It was agreed that a FALLS SIG could advise the CGS on best practices in this area, upon request speak for the Society on the prevention of falls and fall-related injuries to external parties, organize sessions on falls and fall-related injuries at future CGS scientific meetings (based on the comments and concerns raised by FALLS SIG members such as those mentioned at the April 16, 2016 meeting), 
and advocate both internally and externally for those at risk for falls, clinicians striving to provide evidence-based fall preventive care, and investigators studying the topic.

The main goal of the meeting was to gauge the degree of interest in creating within the CGS a group of clinicians and investigators interested in falls as a geriatric syndrome and in the prevention of falls and fall-related injuries. By your response, we can say there is sufficient interest to launch a FALLS SIG. Over 50 individuals attended and 43 provided their email addresses, so we can initiate a community of practice focused on this issue.

Based on this we approached the Council of CGS about recognition of the FALLS SIG. We are pleased to say that our request was viewed favourably. As we are the first SIG established within the CGS, we will have to work with Council to develop a process and structure that meets the needs of members and contributes to the strength of the CGS. There is much we can learn from our colleagues in other national organizations on the opportunities and challenges of SIGs. We plan to let the planning committee of the 2017 Annual Scientific Meeting know of our willingness to help organize a session on falls, and we hope to arrange a space and time for us to meet in Toronto. We plan on using the Society's website to disseminate information about the FALLS SIG and useful resources for members - please watch for this.

\section{CONFLICT OF INTEREST DISCLOSURES}

The authors have no conflicts to declare.

\section{REFERENCES}

1. American Geriatrics Society. AGS/BGS Clinical Practice Guideline: Prevention of falls in older persons. Summary of recommendations. Available From: Http://Www.American geriatrics.Org/Health_Care_Professionals/Clinical_Practice/ Clinical_Guidelines_Recommendations/Prevention_Of_Falls_ Summary_Of_Recommendations. Accessed September 21, 2016.

2. British Geriatrics Society. $17^{\text {th }}$ International Conference on Falls and Postural Stability, Sept. 16, 2016, Edinburgh, Scotland. Available from: http://www.bgs.org.uk/pdfs/1016bgsfalls.pdf. Accessed September 21, 2016.

3. American Geriatrics Society. Sections \& special interest groups. Available from: http://www.americangeriatrics.org/about_us/ who_we_are/sections_special_interest_groups/. Accessed September 21, 2016.

4. British Geriatrics Society. Special Interest [website page]. Available from: http://www.bgs.org.uk/index.php/special interest-main . Accessed September 21, 2016.

5. Sri-on, J, Tirrell GP, Lipsitz LA, Liu SW. Is there such a thing as a mechanical fall? Am J Emerg Med. 2016;34(3):582-85.

Corresponding author: David B. Hogan, MD, FRCPC, Division of Geriatric Medicine, Department of Medicine, HSC-3330 Hospital Dr. NW, Calgary, AB T2N 4N1, Canada

E-mail: dhogan@ucalgary.ca 